\title{
Aprendizagem significativa do conceito de polígono e as tomadas de decisão de uma professora de matemática
}

\author{
Significant learning of the concept of polygon and the decision-makings \\ of a mathematics teacher
}

\author{
Odalea Aparecida Viana ${ }^{1}$ \\ Ana Carolina Igawa Barbosa ${ }^{2}$
}

\begin{abstract}
Resumo. O trabalho apresentado tem por objetivo analisar as decisões de uma professora de matemática no processo de elaboração e aplicação de uma sequência didática que visava à aprendizagem do conceito de polígono no ensino da Matemática. O trabalho foi desenvolvido junto ao Mestrado Profissional em Ensino de Ciências e Matemática (PPGECM) da Universidade Federal de Uberlândia (UFU) e direcionado a alunos do sexto ano do ensino fundamental. As aulas foram gravadas em áudio e vídeo e utilizaram-se folhas com registros dos alunos. Foram elencadas quatro tomadas de decisão relativas a: (a) elaboração do material de aprendizagem (livro didático ou material próprio); (b) estratégia de ensino (recepção verbal ou descobrimento); (c) promoção dos diálogos (definições formais ou informais) e (d) condução da postura de aprendizagem (significativa ou mecânica), tendo como base a teoria da aprendizagem significativa de David Ausubel. A análise qualitativa e explicativa, dentro do escopo da chamada pesquisa do professor, evidenciou que a professora decidiu por construir um material potencialmente significativo; por encaminhar a aprendizagem por recepção verbal; por promover diálogos que resgatavam as palavras dos próprios estudantes, mas com incentivo às definições formais, e por conduzir a aula de modo a incentivar a postura de responsabilidade para aprendizagem significativa.
\end{abstract}

Palavras-chave. Educação Matemática, psicologia da Educação Matemática, ensino de Geometria.

\footnotetext{
${ }^{1}$ Universidade Federal de Uberlândia, odaleaviana@gmail.com

${ }^{2}$ Governo do Estado de Minas Gerais, carol_igawa@hotmail.com
} 


\begin{abstract}
The objective of this work is to analyze the decisions of a mathematics teacher in the process of elaborating and applying a didactic sequence that aimed at learning the concept of polygon. The work was developed within the scope of Professional Master in Science and Mathematics Teaching of the Programa de Pós Graduação de Ensino de Ciências e Matemática (PPGECM) - Universidade Federal de Uberlândia (UFU) and it was directed to students of the sixth year of elementary school. The classes were recorded in audio and video, and printed sheets with students registration were used. Four decisionmakings were listed, and they were related to: (a) elaboration of learning material (textbook or proper materials); (b) teaching strategy (verbal reception or discovering); (c) promotion of dialogues (formal or informal definitions) and (d) conduction of learning posture (meaningful or mechanical), with David Ausubel - s Meaningful Learning Theory as a basis. The qualitative and explanatory analysis, within the scope of the so called teacher research, showed that the teacher decided to build a potentially significant material; to direct learning through verbal reception; to promote dialogues that rescued the own words of the students, but encouraging formal definitions; and to lead the class in a way that encourages a posture of accountability for meaningful learning.
\end{abstract}

Keywords. Mathematical Education, psychology of Mathematical Education, Geometry teaching.

\title{
1 Introdução
}

As muitas críticas que são feitas ao chamado ensino tradicional - este entendido como o ensino por narrativa, a transmissão de conhecimentos e a aprendizagem completamente dirigida por recepção verbal - e a constante valorização de metodologias alternativas minimamente dirigidas - em que se incluem a resolução de problemas, o aprender fazendo e as estratégias de investigação/descobrimento - podem levar o professor de matemática a duvidar dos seus próprios métodos de conduzir as aulas no ensino fundamental. No caso do ensino dos tópicos básicos da geometria plana - por exemplo, o conceito de polígono, tema deste trabalho - o professor deve tomar decisões que vão desde fazer com que os alunos explorem as formas presentes no cotidiano de maneira criativa e dinâmica até levá-los a definir os conceitos com um mínimo de precisão e rigor.

A aprendizagem de conceitos por recepção verbal é defendida por David Ausubel no âmbito da psicologia educacional. Foram destacados, para este trabalho, alguns elementos da teoria apresentados em Ausubel (2003). O primeiro é a definição de um contínuo que vai da aprendizagem significativa até à mecânica. $\mathrm{O}$ segundo refere-se a outro contínuo que é relativo às estratégias de ensino (descobrimento e recepção) e à independência 
entre essas estratégias e os tipos de aprendizagem. Outro ponto teórico refere-se à organização hierárquica de um material didático potencialmente significativo e aos processos de diferenciação progressiva e reconciliação integrativa. Tem-se, também, a definição do papel fundamental da linguagem na instrução por recepção verbal para a aprendizagem significativa de conceitos e proposições. Finalmente, destaca-se a postura do estudante frente à aprendizagem significativa.

A teoria da aprendizagem significativa foi utilizada por uma professora (BARBOSA, 2018) como fundamentação para a elaboração e a aplicação de uma sequência didática direcionada a alunos do sexto ano do ensino fundamental e que objetivava a aprendizagem do conceito de polígono. A sequência deu origem ao Produto Educacional exigido no âmbito do Mestrado Profissional em Ensino de Ciências e Matemática da Universidade Federal de Uberlândia. Apesar de a dissertação já conter várias análises acerca dos resultados, foram verificados outros elementos da experiência que mereciam um estudo mais adequado. Entre esses, a série de tomadas de decisão da professora durante as fases de elaboração e aplicação da sequência, como aquelas que promoveram a confecção de materiais, a ordem de apresentação dos conteúdos, a linguagem utilizada e a condução das atividades na sala de aula.

A análise das referidas tomadas de decisão pode ser entendida no âmbito da chamada prática docente reflexiva, conforme Perrenoud (1999). O autor explica que a prática reflexiva docente não acontece apenas quando o professor está frente a um obstáculo, um problema, um fracasso etc., mas que ela se faz de maneira metódica ao longo de todas as ações profissionais. É por meio da reflexão sobre a prática que o professor constrói seu conhecimento, definido como o conjunto de esquemas de pensamento e de ação; este, por sua vez, determinará as suas percepções e interpretações que influenciarão a constante tomada de decisões.

Assim, com vistas a contribuir com aspectos ligados à formação continuada do professor de matemática, questionou-se quais foram as tomadas de decisão mais importantes no processo de elaboração e aplicação da referida sequência didática. Analisar essas decisões tendo por fundamentação os citados elementos teóricos relativos à aprendizagem significativa é o objetivo deste trabalho.

\section{O conceito de polígono e os elementos da teoria da apren- dizagem significativa}

A Base Nacional Comum Curricular (BNCC) (BRASIL, 2017) indica que o trabalho com as figuras geométricas exige do aluno não apenas o reconhecimento, mas a capacidade de 
identificar e nomear propriedades e de relacioná-las entre si, de classificar e de construir figuras, além de realizar composições e transformações geométricas.

Entre os vários conceitos que são estudados no ensino fundamental, destaca-se o polígono, que pode ser definido como "toda linha poligonal simples e fechada" ${ }^{1}$. O documento orienta que o aluno deve reconhecer e nomear polígonos de acordo com o número de lados, vértices e ângulos, diferenciar polígonos e não polígonos, classificar em regulares e não regulares e ainda determinar outros elementos e propriedades; sugere também que sejam utilizados materiais de desenho ou tecnologia digital na sala de aula. Na revisão da literatura a respeito da questão da aprendizagem de conceitos em geometria, foram identificadas dificuldades dos alunos nessa área de conhecimento, que podem ser vistas em Proença e Pirola (2009). Vários trabalhos sugerem metodologias diferenciadas para a prática do professor em sala de aula, algumas delas apontadas por Santos e Bairral (2015), Silva, Boiago e Viana (2012) e Souza et al (2014), dentre outros.

A questão da aprendizagem de conceitos - estes definidos como objetos, eventos, situações ou propriedades que possuem atributos comuns de critérios comuns e que são representados por meio de algum símbolo ou signo - pode ser estudada no âmbito da teoria da aprendizagem significativa, conforme pode ser visto em trabalhos como Brum e Schuhmacher (2013), Freitas e Viana (2014) e Pivatto e Schuhmacher (2013), entre outros.

O ponto mais importante da teoria de Ausubel (2003) é a definição de aprendizagem na forma de um contínuo que vai da significativa até a mecânica. Na aprendizagem significativa, há fatores afetivos e motivacionais que influenciam o emprego do esforço cognitivo necessário para mobilizar os conceitos subsunçores presentes na estrutura cognitiva de modo a integrá-los aos novos conhecimentos. Na aprendizagem mecânica, há carência de significados e de sentidos, ou seja, pouca associação com os conceitos ou procedimentos relevantes que o aluno possui; neste caso, as relações estabelecidas serão restritas e aleatórias, o que leva à memorização e a pouca retenção do conteúdo aprendido.

Ausubel (2003) define outro contínuo quanto às estratégias de instrução planejadas para estimular a aprendizagem: da recepção verbal até a aprendizagem por descobrimento autônomo. No primeiro extremo, a aprendizagem por recepção acontece quando o conteúdo total a ser aprendido é organizado e apresentado pronto ao aluno. Já no outro extremo, na aprendizagem por descoberta, o conteúdo principal não é dado, mas deve ser descoberto de modo independente pelo aprendiz, seja por meio de resolução de problemas, de experimentos em laboratórios etc. $\mathrm{O}$ autor define também a independência entre os dois contínuos citados, o que leva à compreensão de que a aprendizagem sig-

\footnotetext{
${ }^{1}$ Há outras definições um pouco distintas desta, conforme pode ser visto em Proença (2008) e Domingos (2010).
} 
nificativa e a aprendizagem mecânica podem acontecer tanto por meio de atividades de descobrimento como de atividades de recepção verbal.

Neste trabalho, será dado destaque à aprendizagem por recepção verbal; esta, de acordo com o autor, não é necessariamente memorizada ou passiva na medida em que se utilizem métodos de ensino expositivos que atendam, no mínimo, a três requisitos: (1) uma análise cognitiva que deve ser realizada para constatação de quais os aspectos mais relevantes presentes na estrutura cognitiva do aprendiz para que o novo material seja potencialmente significativo; (2) algum grau de reconciliação com as ideias existentes na estrutura cognitiva do aluno, ou seja, reconhecimento de semelhanças e de diferenças e também a resolução de contradições reais ou aparentes entre conceitos e proposições novos e já enraizados; e (3) reformulação do material em termos de antecedentes intelectuais particulares e do vocabulário do aprendiz.

A aprendizagem significativa deve atender aos princípios de diferenciação progressiva, de reconciliação integradora e de consolidação - estes compõem o terceiro ponto teórico adotado neste trabalho. O princípio de diferenciação progressiva relaciona-se com a hierarquia existente nas matérias escolares, em termos de abstração, generalidade e inclusão e garante que o estudante diferencie os significados das ideias; este processo está mais relacionado à aprendizagem subordinada ${ }^{2}$ e acontece de forma progressiva. Já o da reconciliação leva o aprendiz a integrar os significados, delineando as diferenças e as similaridades entre ideias relacionadas: o processo relaciona-se com a aprendizagem superordenada $^{3}$. Finalmente, a consolidação é alcançada por meio da confirmação, correção e clarificação e deve ser buscada durante o processo - quando o professor retoma, promove novas interações sobre o mesmo assunto etc. - e também ao final do tema, revendo e aplicando o conteúdo aprendido em novas situações de aprendizagem.

Ausubel (2003) destaca a importância da linguagem nos processos de aprendizagem significativa: deve-se à linguagem e ao simbolismo a possibilidade das formas complexas de funcionamento cognitivo. De acordo com o autor, a linguagem não exerce apenas o papel de comunicação: ela tem características operativas na aprendizagem significativa, influencia a natureza e o produto dos processos cognitivos envolvidos na aquisição de novas ideias abstratas e aumenta a manipulação de conceitos e de proposições, já que por meio das propriedades representacionais da palavra ocorre o aperfeiçoamento das compreensões subverbais emergentes na aprendizagem. Essa perspectiva contrasta, portanto, com aquela que interpreta a aprendizagem verbal como a que consiste simplesmente em

\footnotetext{
${ }^{2} \mathrm{Na}$ aprendizagem subordinada, a nova ideia que está sendo aprendida se encontra hierarquicamente subordinada a uma ideia preexistente na estrutura cognitiva.

${ }^{3}$ Neste tipo de aprendizagem, existem ideias já estabelecidas a1, a2, a3 ... que passam a ser reconhecidas como exemplos mais específicos da ideia nova mais geral A. Esta ideia supraordenada A é definida por um novo conjunto de atributos de critério que abrangem as ideias subordinadas anteriores.
} 
verbalismos naturais apreendidos por memorização. Ao contrário, as propriedades representativas das palavras facilitam os processos de transformação envolvidos no pensamento, o que pode contribuir para a criação de significados.

A linguagem do professor tem papel essencial, seja na aprendizagem por recepção seja por descoberta e Ausubel (2003) destaca duas formas de atuação docente, a que ele chama de assistência externa: a orientação e a incitação. Como orientador, o professor atua em situações em que os conteúdos não são dados de forma acabada ao aluno, ou seja, na aprendizagem por descoberta guiada; já no processo de aprendizagem por recepção verbal ele pode incitar o aluno acerca dos conceitos a serem aprendidos, isto é, dar uma assistência parcial de modo que as ideias âncoras fiquem disponíveis para a criação de significados.

Finalmente, a postura de aprendizagem significativa se verifica quando o estudante assume uma responsabilidade adequada pela própria aprendizagem. Isso pode ser efetivado quando ele aceita a tarefa de aprender ativamente, procurando compreender o material de instrução que é apresentado pelo professor. Esta postura também é evidenciada quando o aprendiz tenta, de forma genuína, integrar o conteúdo novo nos conhecimentos que já possui, não evitando o esforço cognitivo para a criação de significados verdadeiros, e decide fazer as perguntas necessárias sobre aquilo que não compreende (AUSUBEL, 2003). Convém acrescentar que a aquisição de significados exige um material de aprendizagem que seja organizado de tal maneira a ter significação lógica ou potencial, isto é, um material que possibilite aos estudantes relacionar, de maneira não arbitrária e não literal, as ideias novas com aquelas já existentes. Já o significado psicológico ou verdadeiro é idiossincrático e é resultante da significação lógica e do mecanismo de aprendizagem significativa; este se caracteriza pela disponibilidade, estabilidade, longevidade e clareza das ideias ancoradas e respectiva capacidade de discriminação quer de ideias novas do material de aprendizagem, quer de ideias ancoradas relevantes na estrutura cognitiva particular do aprendiz.

Evidentemente, a aprendizagem significativa não é explicada apenas pelos pontos aqui elencados. A teoria apresenta outras definições relativas ao desenvolvimento, à motivação, à retenção, à mediação e aos efeitos da prática, entre outras, que não serão exploradas no presente trabalho.

\section{Objetivos, materiais e procedimentos}

Tem-se por objetivo analisar uma série de tomadas de decisão de uma professora no processo de elaboração e aplicação de uma sequência didática direcionada a alunos de sexto 
ano do ensino fundamental no tema Polígonos ${ }^{4}$.

A sequência didática foi aplicada em alunos do sexto ano de uma escola pública do estado de Minas Gerais. As atividades visavam à formação do conceito de polígono a partir do conceito de linhas poligonais e foram distribuídas ao longo de 15 aulas (50 minutos cada), todas ministradas na própria sala de aula da pesquisadora, duas vezes por semana, nos horários específicos destinados às aulas de geometria. Como materiais, foram utilizados desenhos feitos à mão pela professora, cartões numerados com desenhos de figuras geométricas e também fichas que eram entregues durante ou após as explicações para serem preenchidas pelos alunos, além de projeção de slides, canudos, cola, folhas de sulfite e de papel cartão para outras atividades complementares.

As aulas foram gravadas em áudio e vídeo e as folhas com os registros dos alunos foram recolhidas ao final de cada aula.

No processo de elaboração e aplicação das atividades, foram elencados alguns momentos e/ou episódios em que haveria ao menos duas opções de encaminhamento de ações por parte da professora, o que definiu algumas tomadas de decisão. Sendo elencados pela própria professora, segunda autora deste texto, esses momentos/episódios são descritos e também são identificados os pontos teóricos que subsidiaram a tomada de decisão da docente.

Trata-se de uma análise qualitativa e explicativa, dentro do escopo da chamada pesquisa do professor: esse tipo de investigação tem caráter instrumental e utilitário e revela a preocupação do autor em explicar o fenômeno educativo que ocorre na sala de aula e em buscar o conhecimento da realidade para transformá-la, visando à melhoria das práticas pedagógicas (CARNEIRO, 2008; FIORENTINI \& LORENZATO, 2009; LÜDKE, 2001).

\section{A sequência didática}

Na primeira parte da sequência, as quatro atividades objetivavam a construção dos conceitos de linhas poligonais e não poligonais, linhas poligonais abertas e fechadas, linhas poligonais simples e não simples e a avaliação desses conceitos. O quadro na Figura 1 exemplifica os materiais utilizados nessa parte.

No início de cada atividade, a professora construía um quadro na lousa com duas colunas e desenhava uma figura em cada coluna: estas iriam sustentar uma classificação cujo critério deveria ser identificado pelos alunos. A seguir, ela desenhava uma terceira figura fora das colunas e solicitava aos alunos que observassem as características semelhantes

\footnotetext{
${ }^{4}$ A sequência foi elaborada e aplicada no âmbito do Mestrado Profissional em Ensino de Ciências e Matemática da Universidade Federal de Uberlândia e está disponível como Material de Apoio aos professores em https://repositorio.ufu.br/handle/123456789/22183
} 


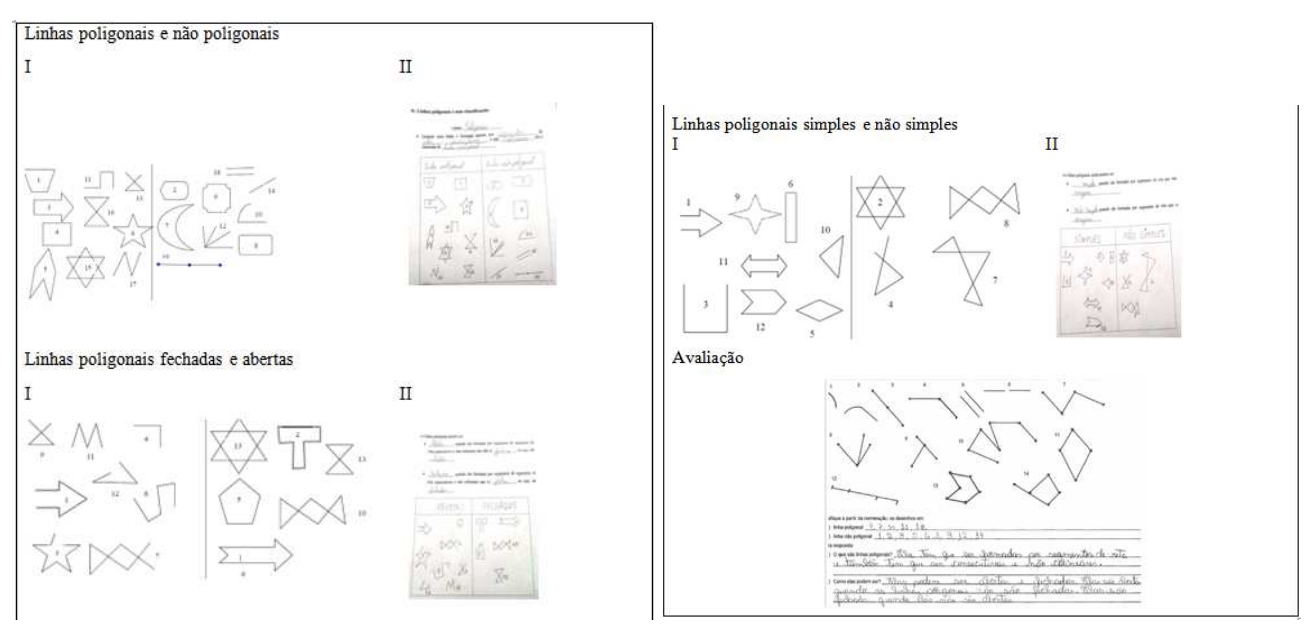

Figura 1: Atividades da primeira parte da sequência.

e distintas entre as duas figuras anteriores e decidissem a qual coluna esta última deveria pertencer. Por exemplo, na primeira atividade, desenhou a figura 1 representando uma linha poligonal; na outra coluna, a figura 2, uma linha não poligonal (ambas aparecem no quadro da Figura 1). Em seguida, desenhou a figura 3 (também consta no quadro da Figura 1), mas não a inseriu em nenhum dos grupos: por meio de discussões, os alunos tiveram que decidir a que grupo esta figura pertencia. Como exemplo da maneira de conduzir a discussão em aula, apresenta-se parte do diálogo no quadro da Figura 2.

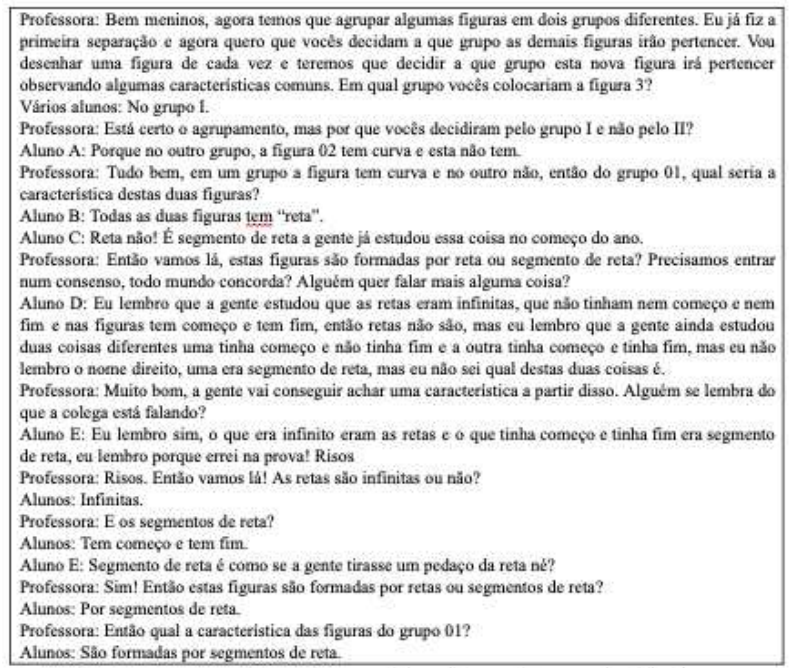

Figura 2: Diálogo promovido na primeira parte da sequência.

As ações se repetiam até que várias figuras fossem classificadas e, então, nomeadas corretamente: linhas poligonais e não poligonais, linhas poligonais fechadas e abertas, linhas poligonais simples e não simples. Ao final da atividade, como forma de avaliar a 
assimilação dos conceitos, uma ficha era entregue a cada aluno para que eles registrassem as definições e desenhassem algumas figuras como exemplos. Na segunda parte, a partir de uma coleção de figuras, os alunos deveriam formar grupos e justificar o critério adotado. Objetivava-se conceituar polígono como sendo linha poligonal fechada e simples. Ainda nesta parte, a professora solicitou que cada aluno fizesse uma composição com pedaços de canudos colados em folha de papel. A seguir, as composições foram decompostas, isto é, partes das formas criadas eram representadas em outra folha para que as linhas fossem identificadas e nomeadas. O quadro na Figura 3 ilustra as figuras utilizadas, as três classificações realizadas e a colagem de canudos com respectiva decomposição e nomeação.

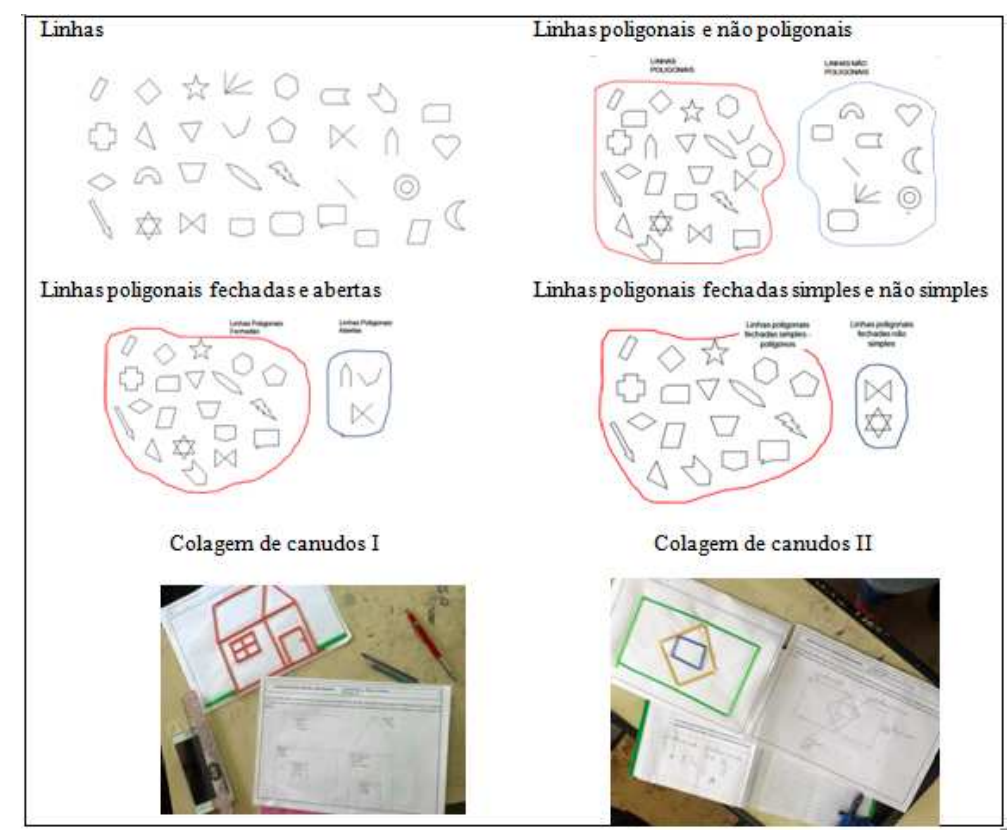

Figura 3: Atividades da segunda parte da sequência.

Cada classificação que era feita pelos alunos tinha que ser justificada na forma de diálogos com a professora. No quadro da Figura 4 tem-se parte de um diálogo.

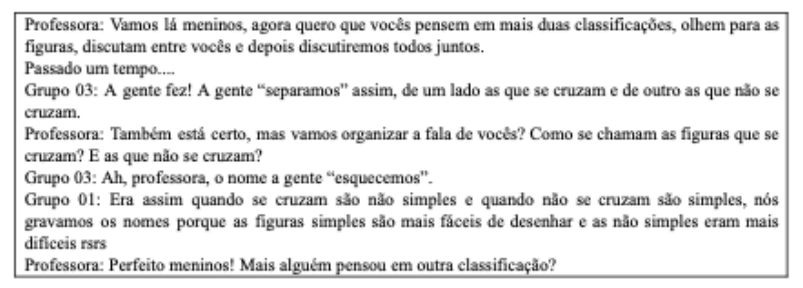

Figura 4: Diálogo promovido na segunda parte da sequência. 
$\mathrm{Na}$ terceira parte da sequência, os polígonos foram classificados de acordo com os seguintes critérios: número de lados e convexidade (Figura 5).

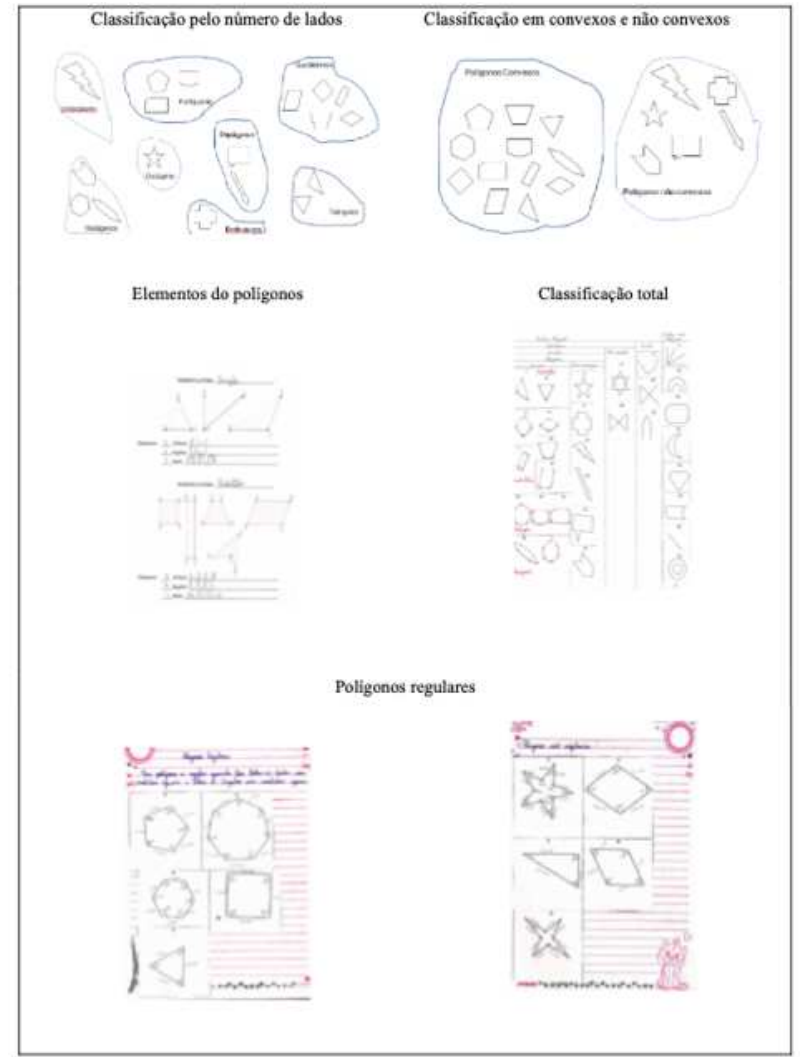

Figura 5: Atividades da terceira parte da sequência.

Muitas discussões ocorreram durante as atividades, sendo destacado o diálogo apresentado na Figura 6.

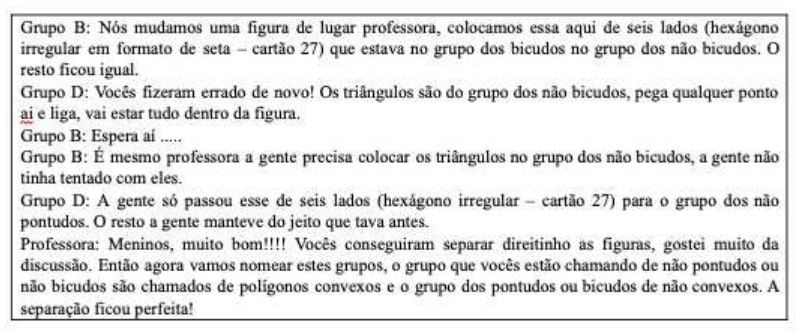

Figura 6: Diálogo promovido na terceira parte da sequência.

Na quarta parte da sequência, chamada de "Meu mundo poligonal", a professora apresentou a atividade por meio de slides contendo vários desenhos na forma de polígonos e que lembravam objetos familiares aos alunos. Alguns polígonos foram explorados, isto é, foram desenhados novamente de modo a evidenciar os lados, vértices e ângulos, sendo 
então nomeados pela convexidade, pela regularidade e pelo número de lados. Os alunos foram solicitados a criar e explorar suas formas, conforme mostra a Figura 7.

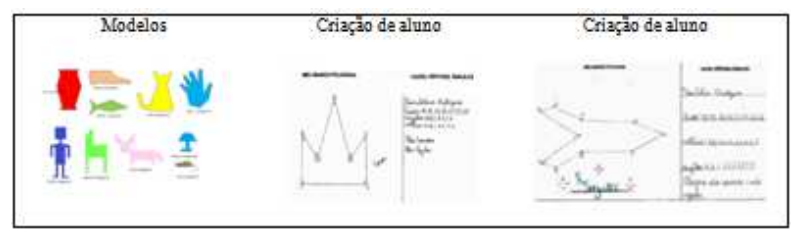

Figura 7: Meu mundo poligonal.

Note que a atividade permitiu que os alunos retomassem a classificação dos polígonos, bem como a nomeação de seus elementos. A última parte da sequência constituiu na confecção de quebra-cabeças: cada aluno recebeu um polígono regular e fez vários cortes no mesmo de modo a formar polígonos. Cada um deles foi nomeado, classificado, sendo destacados seus elementos. A brincadeira final foi montar as peças do quebra-cabeça de modo a formar o polígono inicial. Figura 8.

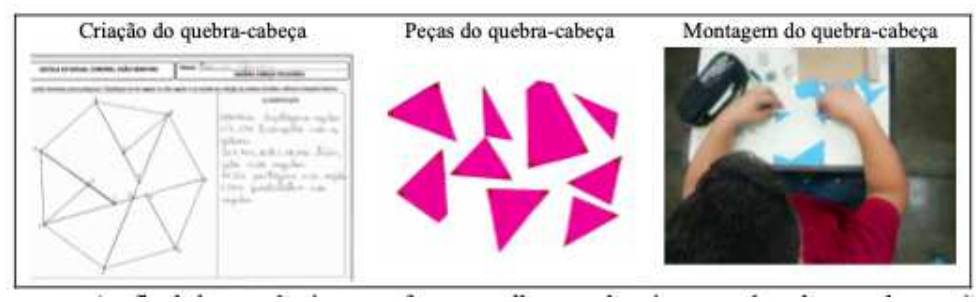

Figura 8: Quebra-cabeça.

Ao final da sequência, a professora colheu os depoimentos dos alunos; alguns são expostos no quadro da Figura 9.

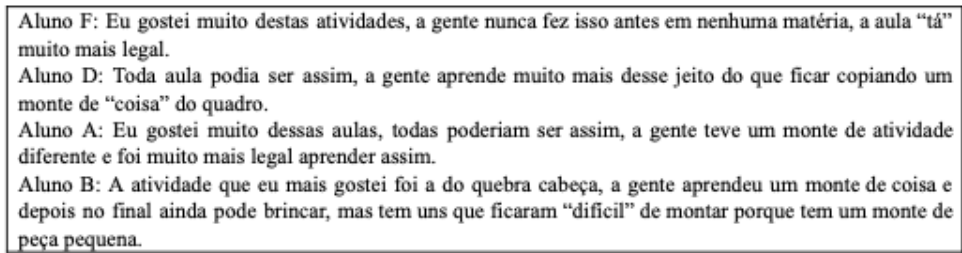

Figura 9: Depoimentos dos alunos ao final da sequência didática.

\section{Analisando as tomadas de decisão}

Apesar de o processo de elaboração e aplicação da sequência envolver uma série de tomadas de decisão da professora, foram destacadas algumas situações com as respectivas 
alternativas que encaminharam as decisões, conforme mostra o quadro na Figura 10.

\begin{tabular}{|c|c|}
\hline Situação & Alternativas \\
\hline I. Elaborando o material de aprendizagem & Livro didático ou material próprio? \\
\hline II. Estratégia de ensino & $\begin{array}{l}\begin{array}{l}\text { Aprendizagem por recepção verbal ou por } \\
\text { descobrimento? }\end{array}\end{array}$ \\
\hline III. Promovendo os diálogos e a linguagem & Definições formais ou não? \\
\hline $\begin{array}{l}\text { IV. Conduzindo a aula e a postura de } \\
\text { aprendizagem }\end{array}$ & Significativa ou mecânica? \\
\hline
\end{tabular}

Figura 10: Momentos e alternativas para tomada de decisão.

\subsection{Elaborando o material de aprendizagem potencialmente signifi- cativo: livro didático ou material próprio?}

Verificando a abordagem de alguns livros didáticos acerca da introdução ao conceito de polígono, observou-se que vários deles iniciam o assunto por meio da apresentação de uma obra de arte; deste desenho são destacadas algumas linhas, poligonais e não poligonais. Em seguida, define-se linha poligonal e apresentam-se alguns exemplos de linhas poligonais abertas e fechadas, simples e não simples. Finalmente define-se polígono como "toda linha poligonal fechada simples" e são apresentados os polígonos convexos e não convexos; os elementos de um polígono e a classificação em regulares e não-regulares e em relação ao número de lados e ângulos.

Apesar de concordar com a sequência dos conteúdos adotada pelos livros didáticos analisados, a professora considerou que seria importante organizar uma estrutura hierárquica para polígonos para não ensinar os conceitos como elementos isolados.

O mapa conceitual, adotado para direcionar as atividades, foi baseado nas ideias de Moreira (1986) que afirma que no processo de ensino e aprendizagem o uso de mapas pode ajudar na definição da hierarquia conceitual, além de permitir a exploração de relações entre conceitos, a evidência de semelhanças e diferenças significativas e a reconciliação de inconsistências reais ou aparentes. Vale salientar que o mapa bidimensional adotado (Figura 11) continha conceitos mais inclusivos escritos em caixa no topo da hierarquia (linhas) e conceitos específicos, menos abrangentes, subordinados aos primeiros, na parte inferior (polígonos convexos/não convexos, regulares/não regulares e distintos pelo número de lados), de modo a evidenciar a organização hierárquica.

Dessa forma, a professora optou por idealizar um conjunto de figuras (linhas) contendo exemplos e não exemplos de cada um dos nomes elencados no mapa da Figura 11. Essas figuras se constituíram ora nos desenhos feitos à mão pela professora no quadro, ora dispostas em cartões numerados que foram distribuídos aos alunos. Havia também 


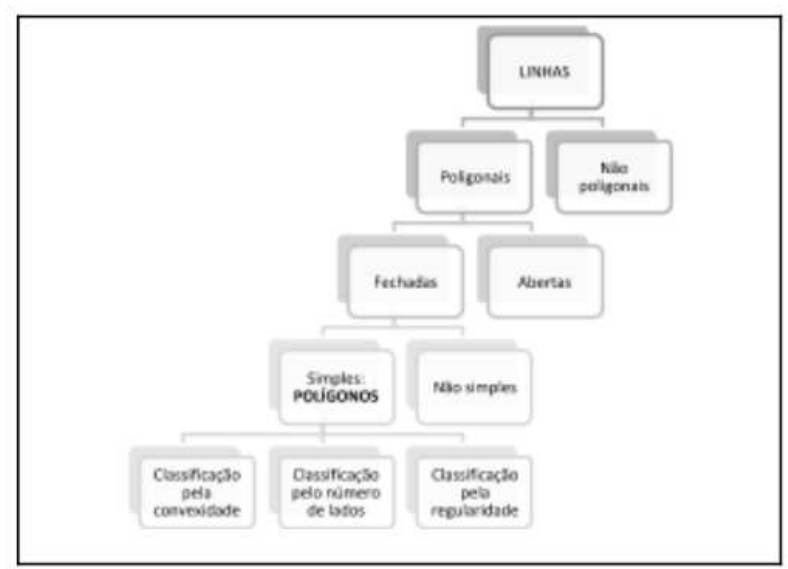

Figura 11: Mapa conceitual adotado na sequência didática.

fichas que eram entregues durante ou após as explicações para serem preenchidas pelos estudantes.

Considerou-se que a apresentação das figuras uma a uma no quadro, seguida da solicitação para que fossem classificadas, levava o aluno a prestar atenção em suas características e a decidir quais delas seriam relevantes para se obter as propriedades comuns desejadas para a formação do conceito. A opção de distribuir várias figuras em diversos momentos da sequência objetivava facilitar o processo de diferenciação progressiva, em que os alunos exploram as relações e identificam semelhanças e diferenças significativas. Isto também favorecia a revisão dos conceitos já vistos em aulas anteriores, a identificação dos atributos por meio de exemplos e não exemplos, a percepção da hierarquia conceitual a ser aprendida e a consolidação das ideias aprendidas. Já as fichas, que objetivavam a descrição e a exemplificação dos conceitos, favoreciam o processo de reconciliação integrativa: ao ter que descrever e exemplificar os conceitos aprendidos, o aluno tinha a oportunidade de identificar algumas inconsistências e formalizar os conceitos.

Conforme Ausubel (2003), um material potencialmente significativo pressupõe: (1) que o próprio material de aprendizagem possa estar relacionado de forma não arbitrária (plausível, sensível e não aleatória) e não literal com qualquer estrutura cognitiva apropriada e relevante (i.e., que possui significado "lógico") e (2) que a estrutura cognitiva particular do aprendiz contenha ideias ancoradas relevantes, com as quais se possa relacionar o novo material. A sequência didática possuía uma organização interna, isto é, os conceitos não estavam apenas sobrepostos e tinha-se a intenção de abordá-los a partir de uma estrutura lógica explícita; além disso, a quantidade de figuras apresentadas favorecia as relações entre as ideias novas e aquelas ancoradas na estrutura cognitiva particular dos alunos. Assim, considerou-se que o material poderia ser considerado como potencialmente significativo. Portanto, a opção da professora de elaborar um material próprio, em 
vez de se valer do livro didático, é explicada pela pretensão de melhores condições para se promover a aprendizagem significativa do conceito de polígono.

\subsection{Estratégia de ensino: aprendizagem por recepção verbal ou por descobrimento?}

No encaminhamento da aula, o professor deve optar entre definir o conceito no início da aula e dar explicações e exemplos ou desenvolver atividades de exploração, de investigação, de resolução de problemas etc., em que os próprios alunos consigam chegar às definições. Segundo Ausubel (2003), uma das dimensões da aprendizagem significativa no âmbito escolar refere-se às estratégias de instrução planejadas pelo professor que podem estimular a aprendizagem por recepção ou por descoberta. Em cada um desses casos, será necessário um grau de assistência do professor. Na aprendizagem pela descoberta, a assistência toma a forma de orientação; na recepção verbal, a de incitação durante as explicações. Evidentemente, fornecer uma orientação completa equivale a apresentar o material pronto e promover a aprendizagem por recepção; já a ausência de qualquer orientação exige uma descoberta completamente autônoma.

No caso analisado, a professora decidiu adotar a estratégia de promover a aprendizagem por recepção significativa, apesar de solicitar aos alunos a identificação de atributos definidores e também alguns critérios próprios de classificação antes de apresentar as definições dos conceitos. Ausubel (2003) afirma que a aprendizagem por recepção verbal não é necessariamente memorizada ou passiva, desde que se utilizem métodos de ensino expositivos baseados na natureza, condições e considerações de desenvolvimento que caracterizam a aprendizagem significativa. Um dos princípios a serem contemplados é o da diferenciação progressiva das ideias que favorece a abstração, a generalização e a inclusão. Já o princípio da reconciliação integradora é facilitado no ensino expositivo quando o professor antecipa e discute, explicitamente, as semelhanças e diferenças confusas entre novas ideias e ideias relevantes existentes e já estabelecidas nas estruturas cognitivas dos aprendizes.

Assim, por exemplo, quando a professora desenhou na lousa as duas figuras (Figura 12), fez com que os alunos notassem que ambas eram formadas por segmentos de reta, mas apenas a da direita era composta por segmentos consecutivos, característica que assume toda linha poligonal. Com o objetivo de consolidar o conceito de linha poligonal, ela antecipou os equívocos e as contradições, clarificando os conceitos de reta, de segmento, segmentos consecutivos e colineares.

A opção pela instrução verbal pode ser notada ao longo de toda a sequência didática e foi motivada pela possibilidade de a professora promover a disponibilidade, a estabili- 


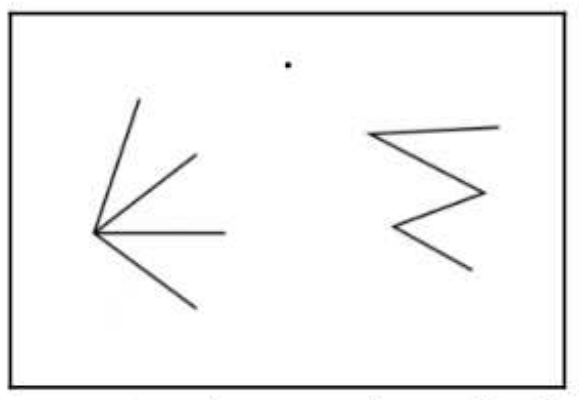

Figura 12: Figuras desenhadas pela professora.

dade e a clareza das ideias ancoradas relativas a segmentos, ângulos etc. Além disso, o questionamento constante que a professora fazia ao longo da sequência didática tinha por objetivo desenvolver a capacidade de discriminação quer de ideias novas do material de aprendizagem, quer de ideias ancoradas relevantes na estrutura cognitiva particular dos alunos.

\subsection{Promovendo os diálogos e a linguagem na sala de aula: definições formais ou informais?}

De acordo com Ausubel (2003), conceitos são ideias organizadas a respeito de algo (objetos, acontecimentos, situações ou propriedades) que possuem atributos específicos comuns e são designados pelo mesmo signo ou símbolo. Ausubel (2003) defende a importância da linguagem na aprendizagem significativa de conceitos, seja por recepção ou por descobrimento, o que implica diálogo e negociação de significados na sala de aula e mediação docente (Moreira, 2012). Nessa perspectiva, a linguagem não exerce apenas o papel de comunicação: ela tem características operativas na aprendizagem significativa, influencia a natureza e o produto dos processos cognitivos envolvidos na aquisição de novas ideias abstratas. Aumentando-se a manipulação de conceitos e de proposições, através das propriedades representacionais das palavras, e aperfeiçoando compreensões subverbais, clarificam-se os significados e tornam-se mais precisos e transferíveis. No caso da geometria, são utilizadas as figuras, as palavras e as sentenças para designar os conceitos e as proposições. A compreensão da linguagem específica da geometria (como lados, vértices, ângulos, segmentos etc.) influencia nas definições dos conceitos e no enunciado de proposições em níveis mais avançados do pensamento geométrico.

Na organização da sequência didática, a professora optou por promover o vocabulário específico da geometria - o que pode ser verificado nas fichas de trabalho e na linguagem utilizada pela professora. Ao solicitar a verbalização das ideias, ou seja, expressar as mesmas verbalmente na forma proposicional, ela objetivou torná-las mais claras, explícitas, 
precisas e bem delineadas.

Apesar disso, a professora aceitava a linguagem informal na descrição inicial de propriedades para que os alunos pudessem criar significados; por exemplo, a nomeação "segmento de reta"partiu da expressão "pedaço da reta" surgida no diálogo apresentado ao final do Quadro 2. No que se refere à aprendizagem de proposições, em que novas ideias se expressam em uma frase ou oração que contenha dois ou mais conceitos, a professora decidiu utilizar também, de início, uma linguagem não formal. Um exemplo é a frase "os triângulos são do grupo dos não bicudos", na primeira tentativa de explicar polígonos convexos, conforme pode ser visto no diálogo mostrado no Quadro 6.

Já o incentivo ao uso da linguagem formal pode ser visto em vários momentos na fala da professora, como em: "também está certo, mas vamos organizar a fala de vocês? Como se chamam as figuras que se cruzam? E as que não se cruzam?" (Quadro 4).

Evidentemente, nem todos os atributos puderam ser explicados convenientemente, como pode ser visto na frase: "... são fechadas quando não são abertas". Mas, quando o aluno escreve a proposição: "todos os segmentos que estão desenhados na mesma reta são colineares", demonstra certo domínio da linguagem ao articular os conceitos de "segmento", de "reta" e de "colineares", ideias supostamente estabelecidas e relevantes existentes na sua estrutura cognitiva.

Da mesma forma, ao expressar verbalmente na forma proposicional: "um polígono é regular quando tem todos os lados com medidas iguais e todos os ângulos com medidas iguais" (Quadro 5) o aluno demonstra ter as ideias claras, explícitas, precisas e bem delineadas.

Dessa forma, a opção da professora pela valorização da linguagem em sala de aula está de acordo com os pressupostos de Ausubel (2003), para quem a verbalização acrescenta muito quer à criação do significado, quer à capacidade de transferência dos produtos do pensamento; assim, deve ser considerada uma parte integral do processo de raciocínio.

\subsection{Conduzindo a aula e a postura de aprendizagem: significativa ou mecânica?}

A aprendizagem significativa exige que os aprendizes manifestem um mecanismo de aprendizagem significativa, ou seja, uma disposição para relacionarem o novo material a ser apreendido, de forma não arbitrária e não literal, à própria estrutura de conhecimentos. No entanto, mesmo que o material tenha sido organizado de modo a ter potenciais significados, se a intenção do aprendiz for a de memorizar as informações como se fossem séries de palavras relacionadas de modo arbitrário, a aprendizagem será mecânica.

Para Ausubel (2003), a "postura de aprendizagem"refere-se à disposição para se apren- 
der de forma mais significativa ou mais mecânica. A postura para a aprendizagem significativa pode ser momentânea, em que o aluno deve prestar atenção e empreender esforços, ou duradoura, quando ele demonstra atitude para "aprender a aprender".

A professora optou pela aprendizagem significativa incentivando uma postura de "aprender a aprender", organizando as atividades em que sempre incentivava os alunos na constante busca do conhecimento. Pode-se notar o direcionamento das atividades por meio de frases como: "eu já fiz a primeira separação e agora quero que vocês decidam a que grupo as demais figuras irão pertencer"; "mas por que vocês decidiram pelo grupo I e não pelo II?". Apesar de algumas atividades de classificação terem sido realizadas pelos alunos dispostos em grupo, a professora optou por registros em fichas individuais, visto que o significado psicológico ou verdadeiro é idiossincrático, sendo resultante da significação lógica do material e do mecanismo de aprendizagem significativa.

As respostas dos alunos: "...eu lembro que a gente estudou que as retas eram infinitas...", "nós gravamos os nomes porque as figuras simples são mais fáceis de desenhar" demonstram que a forma de condução da aula parece ter favorecido a responsabilidade pela própria aprendizagem. Eles pareciam aceitar a tarefa de aprender ativamente quando respondiam as perguntas da professora, sem evitar o esforço cognitivo para lembrar-se de conceitos anteriormente aprendidos e que estavam ancorados em sua estrutura particular.

Ausubel (2003) também indica a aplicação de atividades variadas entre uma tarefa e outra, de modo a garantir a atenção e o emprego do esforço cognitivo. Assim, a professora decidiu desafiar os estudantes a criarem formas com canudos, a produzirem formas poligonais e a elaborar quebra-cabeças. Nota-se que, ao final de cada uma dessas atividades, os alunos voltavam a nomear e classificar as linhas e os polígonos. Isso pode ter contribuído com o processo de consolidação que é alcançado por meio da confirmação, correção e clarificação dos conceitos. Os depoimentos mostrados no Quadro 9 ilustram certa disposição para aprender e espera-se que a aprendizagem tenha sido significativa.

\section{Considerações finais}

Conforme Perrenoud (1999), as tomadas de decisão do professor podem ser decorrentes da reflexão constante sobre sua prática. Quando a reflexão envolve questões ligadas à aprendizagem significativa de conceitos, espera-se que o professor tenha algum conhecimento acerca da teoria de maneira a poder justificar as inúmeras tomadas de decisão que terá que fazer no planejamento e na aplicação de atividades em sala de aula. Evidentemente, existem muitas outras decisões não analisadas nesse trabalho, como as que se referem à retenção do conteúdo, às maneiras de relacionar e aplicar os conceitos em outras áreas da matemática, às formas de avaliação etc.: estas constituem um campo complexo 
da atuação do docente que precisa estar em constante processo de formação continuada. Espera-se que a experiência e as análises aqui apresentadas possam contribuir com o desenvolvimento profissional de professores de matemática, especialmente nas situações em que constem temas ligados à aprendizagem de conceitos em geometria.

\section{Referências}

[1] AUSUBEL, D. P. Aquisição e Retenção de Conhecimentos: Uma Perspectiva

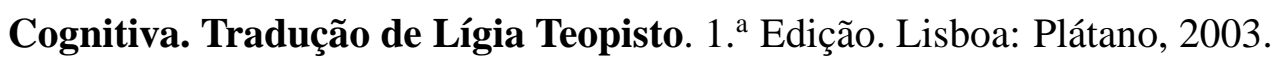

[2] BARBOSA, A. C. I. Aprendizagem significativa do conceito de polígono: uma sequência didática para o sexto ano do ensino fundamental. Dissertação [Mestrado Profissional] - Programa de Pós-Graduação em Ensino de Ciências e Matemática. Universidade Federal de Uberlândia, 2018. Disponível em: « https://repositorio.ufu.br/handle/123456789/22183》. Acesso em 06 dez 2019.

[3] BIANCHINI, E. Matemática - ${ }^{\circ}$ ano. $8^{\text {a }}$ edição. São Paulo: Moderna, 2015.

[4] BRASIL. Base Nacional Comum Curricular. Conselho Nacional de Secretaria de Educação. Brasília: Distrito Federal, 2017. Disponível em: $\ll$ http://basenacionalcomum.mec.gov.br/wp-content/uploads/2018/02/bncc-20dezsite.pdf $\gg$. Acesso em 14 ago 2019.

[5] BRUM, W. P.; SCHUHMACHER, E. Aprendizagem de conceitos de geometria esférica e hiperbólica no ensino médio sob a perspectiva da teoria da aprendizagem significativa usando uma sequência didática. Aprendizagem Significativa em Revista, V.3, N.2, 1 - 21, 2013.. Disponível em: « http://www.if.ufrgs.br/asr/artigos/Artigo_ID45/v3_n2_a2013.pdf $\gg$ Acesso em 14 ago 2019.

[6] CARNEIRO, V.C. Contribuições para a Formação do Professor de Matemática Pesquisador nos Mestrados Profissionalizantes na Área de Ensino. Bolema, Rio Claro (SP), Ano 21, n 29, p. 199-222, 2008.

[7] DOLCE, O.; POMPEO, J. N. Fundamentos de matemática elementar 9: geometria plana. 7. ed. São Paulo: Atual, 1993. v. 9, 1993.

[8] DOMINGOS, J. Um estudo sobre polígonos a partir dos princípios de Van Hiele, 272p. Dissertação (Mestrado em Educação) - Universidade Federal do Espírito do Santo, Vitória, 2010. 
[9] FIORENTINI, D.; LORENZATO, S. Investigação em educação matemática: percursos teóricos e metodológicos. 3ª edição. Campinas: Autores Associados, 2009.

[10] FREITAS, R. F. B; VIANA, O. A. Organizadores prévios para o ensino de semelhança de triângulos: uma experiência de estágio. In: V SEMANA DE MATEMÁTICA DO PONTAL \& I COLÓQUIO DE ANÁLISE MATEMÁTICA DO PONTAL, 2014, Ituiutaba, MG, Anais da V Semana de Matemática do Pontal e I Colóquio de Matemática Aplicada do Pontal, Ituiutba. Mg, 2014.

[11] LÜDKE, M. A complexa relação entre o professor e a pesquisa. In: André, M. (Org.). $O$ papel da pesquisa na formação e na prática dos professores. Campinas: Papirus, p. 27-54, 2001.

[12] MOREIRA, M. A. Mapas conceituais. Cad. Cat. Ens. Fis., Florianópolis, 3(1), p. 17-25, 1986. Disponível em $\ll$ https://periodicos.ufsc.br/index.php/fisica/article/view/7934》. Acesso em 14 ago 2019.

[13] MOREIRA, M. A. ¿Al final, qué es aprendizaje significativo? Qurriculum: Revista de Teoría, Investigación y Práctica Educativa, N. 25, p. 29-56, 2012. Disponível em: «https://lume.ufrgs.br/bitstream/handle/10183/96956/000900432.pdf?sequence= $1 \&$ isAllowed=y $\gg$. Acesso em 14 ago 2019.

[14] MORI, I.; ONAGA, D. S. Matemática: ideias e desafios, $6^{\circ}$ ano. $17^{\mathrm{a}}$ edição. São Paulo: Saraiva, 2012.

[15] PERRENOUD, P. Construir as competências desde a escola. Trad. Bruno Magne. Porto Alegre. Artes Médicas Sul, 1999.

[16] PIVATTO, B., SCHUHMACHER, E. Conceitos de teoria da aprendizagem significativa sob a ótica dos mapas conceituais a partir do ensino de Geometria. REVEMAT. Florianópolis (SC), v. 08, n. 2, p. 194-221, 2013. Disponível em: $\ll$ http://dx.doi.org/10.5007/1981-1322.2013v8n2p194». Acesso em 14 ago 2019.

[17] PROENÇA, M. C. Um estudo exploratório sobre a formação conceitual em geometria de alunos do Ensino Médio. Dissertação (Mestrado em Ensino de Ciências e Matemática) - Universidade Estadual Paulista, Bauru, 2008.

[18] PROENÇA, M. C.; PIROLA, N. A. Um estudo sobre o desempenho e as dificuldades apresentadas por alunos do ensino médio na identificação de atributos definidores de polígono. Zetetiké, Campinas, v. 17, n. 31, 11-45, 2009. Disponível em: 
$\ll$ https://periodicos.sbu.unicamp.br/ojs/index.php/zetetike/article/view/8646723/13625》. Acesso em 14 ago 2019.

[19] SANTOS, R.T.; BAIRRAL, M. A. Aspectos emergentes na construção do conceito de polígono por alunos do $6^{\circ}$ ano de uma escola pública. Vidya, v. 35, n. 1, p. 15-40, jan./jun., 2015.

[20] SILVA, L. R.; BOIAGO, C. E. P.; VIANA, O. A. Formação conceitual em Geometria: uma sequência didática proposta nas ações do PIBID. In: III Encontro Mineiro Sobre Investigação na Escola, 2012, Ituiutaba. Anais III Encontro Mineiro Sobre Investigação na Escola, Ituiutaba: III EMIE, 2012. Disponível em $\ll$ http://www.emie.facip.ufu.br/sites/emie.facip.ufu.br/files/Anexos/Bookpage /Anexos_III_Encontro_Mineiro_Anais_Trabalho_23.pdf $\gg$. Acesso em 28 mai 2019.

[21] SILVEIRA, E. Matemática: Compreensão e Prática - $6^{\circ}$ ano. $3^{\text {a }}$ edição. São Paulo: Moderna, 2015.

[22] SOUZA, A. B.; BARBOSA, A. C. I.; SANTOS, L. K. C. A.; VIANA, O. A. Materiais concretos no processo de formação conceitual de polígonos: uma experiência que "não deu certo"? In: V ENCONTRO MINEIRO SOBRE INVESTIGAÇÃO NA ESCOLA, 2014, Anais V Encontro Mineiro Sobre Investigação na Escola, Uberlândia. MG, 2014.

[23] VAN HIELE, P. Structure and Insight - a theory of mathematics education. Orlando: Academic Press, 1986. 